\title{
LA SALUD ORAL DE LAS MUJERES GESTANTES, SUS REPERCUSIONES Y LOS ASPECTOS QUE INFLUENCIAN SU ATENCIÓN
}

\author{
Sonia Constanza Concha Sánchez \\ Odontóloga U. Santo Tomás, Especialista en Educación y Comunicación para la Salud UIS, \\ Magíster en Epidemiología U. Industrial de Santander, Estudiante Doctorado en Salud Pública \\ U. Nacional de Colombia, Bogotá (Colombia)
}

Correo electrónico: sococosa@yahoo.com

\section{RESUMEN}

La salud oral de las mujeres gestantes no es buena, los cambios sistémicos y orales en la embarazada pueden comprometer no sólo la condición oral también la salud y la vida de la materna, el feto y del recién nacido. Los aspectos que inciden sobre la salud y la atención odontológica de la materna son muchos y deben analizarse de manera integral con el propósito de propiciar cambios que promuevan la salud y la vida de la mujer durante todo su ciclo vital pero en especial durante su embarazo. El objetivo de este artículo es describir los cambios que se presentan en un contexto general y oral en las gestantes; los efectos sobre su salud y la de su hijo y los aspectos que condicionan su atención odontológica. [Concha SC. La salud oral de las mujeres gestantes, sus repercusiones y los aspectos que influencian su atención. Ustasalud 2011; 10: 110 - 126]

Palabras clave: Salud oral, Gestantes, Atención odontológica

\section{ORAL HEALTH IN PREGNANCY, REPERCUTIONS, AND ISSUES THAT INFLUENCE DENTAL ATTENTION}

\section{ABSTRACT}

The oral health in the pregnant is not good; the systemic and oral changes in the pregnant could affect the oral and general health and the life of the woman, the fetus and the new born. Several aspects affect the maternal oral health and the dental attention and they must be analyzed in integral way in order to changes and promote the health and the life of the woman in their vital cycle but especially during her pregnancy. The aim of this paper is to describe the changes that occur in a general context in pregnant women and oral, the effects on their health and that of his son, and the issues that affect their dental care.

Key words: Oral health, Pregnancy, Dental attention

Recibido para publicación: 12 de noviembre de 2011. Aceptado para publicación: 9 de diciembre de 2011

\section{INTRODUCCIÓN}

La condición oral de las mujeres gestantes está lejos de ser buena y la profesión odontológica está en mora de reconocer esta situación y de definir aspectos estructurales y conceptuales que orienten una visión renovada que ofrezca mejores alternativas para la atención bucal de las mujeres embarazadas y con ello una buena condición oral y una mejor calidad de vida.

El embarazo se define como el periodo durante el cual la mujer alberga en su útero el óvulo fecundado por el espermatozoide que se desarrolla hasta alcanzar la madurez del feto y que culmina con el parto. A pesar de ser una condición normal, durante esta etapa suceden en la mujer una serie de cambios a nivel personal, físico, mental, social y fenomenológico que condicionan la vida y la salud de la mujer y la de su hijo. El sistema estomatognático no es ajeno a estas modificaciones, pues los cambios a nivel general repercuten en forma directa o indirecta sobre la condición bucodental de la mujer embarazada, que se podrían manifestar como un aumento en la frecuencia de las patologías orales como son la caries, la enfermedad periodontal y las alteraciones de la mucosa bucal, por referir las más usuales. Estas modificaciones tienen serias repercusiones sobre la condición de salud tanto de la gestante como del feto, pues la evidencia aunque sin ser concluyente, relaciona las infecciones bucodentales con eventos como el parto pre-término, el bajo peso al nacer, la diabetes gestacional y la preclampsia, entre otros. ${ }^{1}$ A pesar de esta situación, son frecuentes las enfermedades orales en las mujeres gestantes, lo que parece indicar que las mujeres embarazadas o no acuden a la consulta en forma oportuna o no recibe 
la atención odontológica adecuada por parte de los profesionales; sin embargo, en la literatura revisada no se evidencian los aspectos, que en forma integrada permitan comprender la situación, pues se han abordado de manera fragmentada y parcial.

Con el ánimo de lograr una mejor comprensión del tema se exploró teóricamente el embarazo y sus cambios, incluidos los que tienen que ver con el sistema estomatognático; también se retomaron aspectos relacionados con la epidemiología de las patologías orales durante la gestación, además de los potenciales riesgos que estas alteraciones representan para la mujer embarazada, el feto o el recién nacido; igualmente, se analizaron los criterios relacionados con la atención de las gestantes y en particular con la atención odontológica con énfasis en las embarazadas. Finalmente, se refiere lo reportado en la literatura con respecto a lo percibido por las gestantes y los odontólogos, la influencia de la familia, los determinantes sociales, la cultura, el sistema de salud, los aspectos económicos, las políticas, la infraestructura institucional y urbana, y el ambiente, frente la asistencia y a la atención odontológica de la gestante.

De esta forma, el objetivo del presente escrito es describir los cambios que se presentan a nivel general y oral en las gestantes; los efectos sobre su salud y la de su hijo, y los aspectos que condicionan su atención odontológica.

\section{EL EMBARAZO Y SUS CAMBIOS}

Durante el embarazo pueden ocurrir múltiples cambios que acontecen a diferentes niveles. Los biológicos hacen alusión a las modificaciones morfofisiológicos que suceden en la mujer embarazada. Los socioculturales refieren las variaciones que se dan en la gestante y en su grupo social y que tienen que ver con los conceptos de maternidad construidos en el contexto. Los psicológicos hacen alusión a los cambios emocionales que se evidencian en la gestante durante su embarazo. Es importante además referir las variaciones en las percepciones que suceden tanto en las gestantes como en los profesionales que las atienden como resultado del proceso mismo del embarazo que es vivenciado de manera particular por cada sujeto. ${ }^{2}$ Sin pretender ser exhaustiva, a continuación se describirán cada uno de estos apartes y sus potenciales relaciones con la salud bucodental de las gestantes.

\subsection{A nivel biológico}

A nivel biológico se observa que durante el periodo de gestación ocurren en la madre cambios importantes en el sistema endocrino que se manifiestan como un aumento en la producción de hormonas y de ello se deriva una serie modificacionesde orden sistémico que propician que el óvulo fecundado se implante en el útero. Durante el embarazo se incrementa la liberación de estrógenos producidos tanto por los ovarios como por la placenta; también hay mayores niveles de progesterona, pues esta es responsable de las funciones orientadas a mantener viable el embarazo; acciones como la preparación del endometrio para la nutrición del feto, la disminución en la contractilidad del útero para evitar abortos espontáneos y la de asociarse con los estrógenos para preparar el momento de la lactancia. La liberación de la progesterona en la mujer durante la gestación también es importante porque, además de mediar el proceso de embarazo como tal, su aumento repercutirá en los sistemas vitales como son el nervioso, el cardiovascular, el gastrointestinal, el renal, el sistema inmune y el respiratorio, para generar cambios, que afectarán a la madre y que deben ser monitoreados por los profesionales de la salud. ${ }^{3,4}$

En el sistema nervioso central se evidencia síntomas neurológicos durante el primer trimestre del embarazo como fatiga, náuseas, y vómito. También hay una tendencia a producirse síncope e hipotensión postural. Durante el segundo trimestre, estos síntomas disminuyen y la madre siente mayor bienestar. Pero durante el tercer trimestre, de nuevo se incrementan las molestias ya que vuelven las fatigas y la sensación de depresión. ${ }^{3}$

En el cardiovascular, como resultado de la modificación en la función hormonal durante el embarazo, se observa el incremento de los mineralocorticoides en el suero materno que inducen a una retención de sodio, lo que producirá un aumento en el agua corporal e incremento de la cantidad de plasma en un 30\% a 40\%; también habrá una expansión en el volumen intra-vascular pues hay más células rojas. En forma usual, ocurre una ligera elevación de la presión sanguínea, específicamente de la diastólica, lo que puede desencadenar taquicardia y ruidos cardiacos anómalos; en el 90\% de las mujeres embarazadas se presenta un soplo sistólico que es de tipo fisiológico o funcional y generalmente desaparece después del parto. Además, ocurre un fenómeno conocido como síndrome de hipotensión supina, que se manifiesta como una caída abrupta de la presión sanguínea, bradicardia, sudoración, náuseas, debilidad y necesidad de aire cuando la paciente está acostada; estos síntomas se presentan debido al enlentecimiento del retorno del flujo venoso del corazón que resulta de la compresión de la vena cava inferior por la presión que el útero ejerce y que conduce a disminución en la presión arterial, en el gasto cardiaco y la pérdida de la conciencia. En el 
periodo de gestación también pueden ocurrir cambios a nivel sanguíneo, que se manifiestan como cuadros de anemia y una disminución en los valores del hematocrito. La mujer embarazada requiere mayores suministros de hierro como consecuencia del aumento del volumen sanguíneo., ${ }^{3,4}$

Los cambios a nivel de la función respiratoria incluyen disminución en la reserva del volumen debido a la expansión del útero asociado al desarrollo del feto y al incremento en la demanda de oxígeno. Estos cambios en la ventilación pueden causar taquipnea, disnea, hiperventilación, un incremento tanto de la frecuencia respiratoria como de la tasa de ventilación por minuto y que se agravan cuando la gestante está en posición supina. El crecimiento del feto presiona el diafragma que causa un incremento en la presión intra-torácica y aumento en la circunferencia del pecho. Además, el aumento de los estrógenos causa ensanchamiento de los capilares nasales, rinitis, hemorragia nasal y predisposición a infecciones en la vía aérea superior. ${ }^{3,4}$

Las modificaciones gastrointestinales se relacionan con el crecimiento del feto y con los cambios hormonales. Las principales manifestaciones son náuseas, vómito y reflujo; este último se presenta por aumento de la presión a nivel del estómago, vaciamiento gástrico lento y reducción en la función del esfinter gastro-esofágico. Durante el embarazo hay un incremento en la demanda de energía que promueve el crecimiento del feto y la placenta; esto afecta el metabolismo de todos los nutrientes en especial del hierro y del ácido fólico, entre otros; por lo que las gestantes requieren de suplementos nutricionales. ${ }^{4}$

A nivel renal hay un incremento en la tasa de filtración glomerular, lo que genera cambios en la composición química de la sangre y la orina, incremento en la frecuencia urinaria, e infecciones en el tracto urinario. Otros cambios incluyen la disfunción renal que provoca hipertensión, proteinuria y edema que propician con ello la aparición de la preclampsia. ${ }^{4}$

Al referirse a la condición oral de las gestantes es fundamental reconocer al embarazo mismo como un factor que puede llegar a modificar las condiciones orales y particularmente las estructuras dentales y periodontales; pues a lo largo del embarazo, se registra una serie de cambios a nivel hormonal, vascular, inmunológico y celular que aumentan la susceptibilidad a presentar patologías a este nivel. La evidencia parece indicar que los efectos sobre los dientes podrían estar asociados a cambios en el ambiente oral que traen consigo reducción en el pH oral, modificaciones en el flujo salival, alteración en el sistema inmunológico, entre otros; los cuales afectan los mecanismos de remineralización, des- mineralización y la función de los sistemas inmunológicos salivales específicos y no específicos que condicionan el desarrollo de la caries dental. Los cambios en la condición periodontal están determinados por las modificaciones vasculares (una mayor permeabilidad capilar), hormonales (el aumento en los estrógenos), e inmunológicos (el incremento en las prostaglandinas) que hacen que se presente una respuesta exagerada de los tejidos que rodean y soportan la estructura dental ante irritantes que en condiciones similares no se registran en las mujeres no embarazadas. ${ }^{3-7}$

\subsection{A nivel social}

La noción de maternidad da cuenta de complejos procesos socioculturales que tienen variabilidad a través del tiempo en una misma cultura o dentro de ella en las diferentes clases sociales y lo mismo puede decirse si se comparan culturas y/o sociedades. ${ }^{8-12}$ La maternidad representa uno de los eventos más importantes en la vida de una mujer dado que la sociedad y la cultura le han dado un valor especial estableciendo lo que se espera de ella en esta etapa, de cómo debe ser y comportarse para ser una "buena madre". Adicionalmente, la influencia de factores psicosociales tales como los socioeconómicos (empleo, pobreza, y otros), el aislamiento social, los conflictos de pareja, el apoyo social del cónyuge, la familia y los amigos inciden en la forma cómo la gestante percibe su embarazo. ${ }^{9,12}$ Además la inclusión de aspectos relacionados con la cultura, la estructura social, la historia, tienen relación con los estilos de vida, las formas de articulación social, y apoyo social que inciden directa o indirectamente en la concepción que la mujer hace de su embarazo y de los cuidados que adopta. ${ }^{10,11}$

Los aspectos socioculturales también condicionan la salud bucodental de las gestantes, ya que la importancia que la embarazada le da a su estado bucal varía según el estrato socioeconómico, el nivel educativo, la cultura y la etnia a la que pertenece; además, fundamentada en la influencia que ejerce su entorno sociocultural la mujer puede adquirir creencias o adoptar conductas que pueden proteger o afectar su salud oral. ${ }^{13}$

\subsection{A nivel psicológico}

A nivel psicológico se analizan los cambios emocionales que registra la mujer embarazada, es importante anotar que estos pueden explicarse en parte por las modificaciones que se presentan a nivel del sistema nervioso y en otros sistemas; es por ello que se observan signos de depresión como reacciones de ajuste al embarazo, mayor labilidad e hipersensibilidad emocional, pesimismo, preocupación e interés significativo por la salud traducidos en va- 
rias quejas somáticas. Así mismo, hay sentimientos de tristeza por la pérdida del estado anterior, las modificaciones en su independencia, en su estilo de vida y en su apariencia personal. Paradójicamente, tiende a elevarse la autoestima, pues la mujer vive el embarazo como un logro. De igual modo pueden surgir sentimientos de inseguridad, dependencia e introversión. Estas características son de tipo transitorio y están supeditadas al desarrollo y resolución del embarazo. ${ }^{12,14-17}$

Las alteraciones psicológicas en las gestantes pueden tener efecto sobre la salud oral. Los estados de depresión, los sentimientos de tristeza y otros síntomas relacionados podrían influenciar las medidas de autocuidado; lo que se evidencia en el caso de la salud bucal en la reducción en la frecuencia de cepillado y en el uso de la seda dental; así los depósitos de placa dentobacteriana aumentan y sustentados en la hipersensibilidad gingival y en la asociación con otros factores de riesgo relacionados provocan que las patologías orales sean más frecuentes. ${ }^{18}$

\subsection{A nivel de las percepciones}

$\mathrm{Al}$ referirse a las percepciones de las gestantes es importante anotar que la forma como se interpretan los hechos biológicos, psicológicos, socioculturales nos hablan de la manera de entender y dar sentido a la realidad. ${ }^{19}$ Los diversos cambios que se dan en las gestantes pueden ser percibidos de manera diferente por las mujeres embarazadas, las variaciones ya reportadas pueden ser vividas, por la gestante, de manera particular y aunque el embarazo es una situación natural, podría ser calificado, desde el punto de vista de las gestantes, como un suceso grandioso o terrible dependiendo de las circunstancias, el momento, el deseo y las intenciones que la mujer tenga frente a este. La forma como se ve el embarazo está determinada también por la aceptación y la adaptación a los cambios corporales y a las molestias físicas, a la amenaza inexorable del parto con sus riesgos y su dolor. ${ }^{20}$

La relación que la condición bucodental tiene en la construcción que la gestante elabora sobre su boca se refleja en sus creencias y prácticas. La literatura demuestra como las gestantes tienen representaciones equivocadas en la relación embarazo y salud bucal "la pérdida de un diente con cada embarazo", "el niño toma el calcio de los dientes" son asumidas como normales, desconociendo o minimizando la importancia de la condición oral y con ello poco interés en su tratamiento, más aún si estas patologías no tienen manifestaciones notorias o son silenciosas; ${ }^{21}$ así mismo Marc y Col muestran como las mujeres embarazadas tienden a no dar importancia a las manifestaciones orales y a percibir el tratamien- to como innecesario; algunas de las construcciones son producto de la tradición y la cultura pero son apropiados por la gestante de manera diferente de acuerdo a sus experiencias. ${ }^{22}$

$\mathrm{Al}$ analizar las percepciones es importante considerar además que, el cuerpo de las mujeres en gestación es un excelente espacio de observación para el análisis de las representaciones que sobre la gestación hacen tanto las mujeres como los profesionales interesados por el bienestar del feto y de la madre, y que intervienen de formas distintas con un mismo objetivo: conseguir el buen funcionamiento y el mantenimiento del equilibrio entre ambos cuerpos. En las relaciones que se establecen entre mujeres y profesionales de la salud pertenecientes a un mismo contexto cultural se supone que ambos comparten un idéntico universo simbólico, lo que facilita la comprensión y la efectividad de los cuidados; sin embargo, esto no siempre ocurre así, pues los eventos en salud son experimentados de manera diferente y esto se relaciona con las formas individuales de interpretar una misma realidad. ${ }^{19}$ Con esta base, se puede llegar a suponer que entre los odontólogos y las gestantes existen diferencias en la interpretación de lo que es el embarazo y dificultades en la comunicación lo que podría llegar a entorpecer la atención, la asistencia y la adherencia a los planes de tratamiento y esto podría explicar la elevada frecuencia de las enfermedades bucodentales en las gestantes.

Una de las mayores dificultades enfrentadas al referirse al embarazo y sus cambios es la mirada fraccionada que se hace desde las diferentes disciplinas aspecto que compromete no sólo comprensión de este evento en el marco del ciclo de vida de la mujer sino también en el proceso de brindarle una atención integral, comprensiva y de calidad a la gestante.

\section{EPIDEMIOLOGÍA DE LAS PATOLOGÍAS ORA- LES DURANTE LA GESTACIÓN}

Al considerar lo ya expuesto y retomar lo planteado por Vera - Delgado y colaboradores se puede afirmar que las mujeres embarazadas pueden ser consideradas como pacientes de alto riesgo de padecer complicaciones orales tanto en los tejidos blandos como en los dentarios. ${ }^{23}$ Para comprender el proceso salud enfermedad en la gestante es necesario profundizar en conceptos básicos como son la caries dental, la enfermedad periodontal, el granuloma piógeno, las patologías de la mucosa oral, la erosión dental, entre otros.

\subsection{Patologías dentales}

La caries dental se define como una enfermedad crónica que se caracteriza por la desmineralización 
y destrucción progresiva de los tejidos duros de los dientes y es de origen multifactorial. A pesar de que hay una convicción general que el embarazo es perjudicial para los dientes, no está claro su efecto en la iniciación o progresión de la caries dental. En términos epidemiológicos esta patología se expresa como prevalencias o incidencias, pero para los estudios de base poblacional se utiliza con mayor frecuencia el índice de dientes cariados, obturados y perdidos (COP), ya sea expresado por diente (COPd) o por superficie (COPs) ${ }^{24}$ Los estudios a nivel nacional e internacional ilustran cómo la prevalencia de caries dental en las gestantes oscila entre $81,2 \%$ y $94,1 \%$ con frecuencias de caries similares a las reportadas en el III Estudio Nacional de Salud Bucal de 1999 para la población general $(88,9 \%)$ y para las mujeres $(89,5 \%){ }^{21,24,25}$ En este mismo estudio el promedio del COPd fue de 10 para población entre los 20 y 34 años mientras que este indicador en estudios realizados con gestantes, con rangos de edad similares, alcanza medias que oscilan entre 7,6 y 13,3 dientes cariados, obturados y perdidos. ${ }^{23,24}$

En los dientes también se observa la erosión dental que es otra condición que puede afectar a la mujer embarazada; esta se define como la pérdida de sustancia dentaria como resultado de la acción de ácidos y en este caso como efecto del vómito y la exposición de los dientes a los ácidos estomacales. A pesar de la relación que la literatura reporta frente al embarazo no se logró identificar en los artículos revisados la frecuencia con que esta condición se presenta en la mujer embarazada. ${ }^{26}$

\subsection{Patologías de la mucosa bucal}

Existen diferentes manifestaciones en la mucosa bucal relacionadas con el embarazo. Las aftas recurrentes se describen como ulceraciones dolorosas que aparecen en la mucosa bucal y surgen en forma solitaria o múltiple, son frecuentes en el embarazo y su etiología obedece a deficiencias de hierro y vitamina B12. La queilitis angular, descrita como una lesión ubicada en la comisura de los labios, (QA) se evidencia como consecuencia de la anemia durante el periodo de gestación o por la candidiasis; la Cándida albicans, agente relacionado con la QA, está presente en cavidad oral durante el embarazo asociado a los cambios hormonales, caída del pH salival, lo que favorece el crecimiento de este microorganismo oportunista. Debido a las alteraciones inmunológicas y los desequilibrios hormonales en el embarazo se puede observar un aumento en la frecuencia de herpes recurrente labial, que se manifiesta como vesículas y erosiones en los bordes del labio. La lengua depapilada o ausencia de papilas gustativas, también puede observarse y se caracteriza por zonas centrales irregulares, no induradas, que varían de un color rosa a rojo, con pérdida de papilas en la cara dorsal de la lengua y surge como consecuencia de tres factores comunes en las mujeres embarazadas: el primero, el vómito frecuente que depapila lengua por la acción erosiva de los ácidos; el segundo determinado por la higiene deficiente que con frecuencia se evidencia durante esta etapa como consecuencia a la hipereactividad del reflejo nauseoso; y el tercero se asocia a los procesos anémicos por deficiencias nutricionales.

Otra lesión de los tejidos blandos que puede observarse es la leucoplasia, término que describe lesiones blancas de la mucosa oral, que aparecen en forma de placas y se relacionan con las hormonas femeninas, la deficiencia de vitamina A y B lo que induce metaplasia y queratinización de ciertas estructuras epiteliales. La estomatitis subprotésica es una patología que se ubica en el paladar duro de pacientes portadores de prótesis dentales, y se asocia con el embarazo como efecto del aumento en la ingesta de carbohidratos, pues estos se constituyen en un excelente medio de cultivo de microorganismos de la placa dentobacteriana y predisponer a infecciones secundaria de tipo candidiasis. Las deficiencias nutricionales frecuentes en las gestantes como bajos niveles de hierro, ácido fólico y vitamina B12, relacionadas con la anemia provocan reducción en las defensas del organismo y esto puede agravar la estomatitis subprótesis en las embarazadas. La prevalencia de lesiones en la mucosa bucal en gestantes se presentan en la tabla $1{ }^{27}$

Tabla 1. Prevalencia de lesiones de mucosa bucal en paciente embarazadas.

\begin{tabular}{lc}
\hline \multicolumn{1}{c}{$\begin{array}{c}\text { LESIONES MUCOSA BUCAL } \\
\text { (Gingivitis concomitante) }\end{array}$} & $\begin{array}{c}\text { FRECUENCIA } \\
\mathbf{n}(\%)\end{array}$ \\
\hline Estomatitis subprotésica & $16(6,4)$ \\
Úlcera aftosas & $16(6,4)$ \\
Lengua depapilada & $11(5,6)$ \\
Leucoplasia & $11(4,4)$ \\
Glositis migratoria benigna & $8(4,4)$ \\
Lengua fisurada & $7(3,2)$ \\
Historia Herpes labial & $6(2,8)$ \\
Queilitis angular & $3(1,2)$ \\
Fibroma traumático & $3(1,2)$ \\
Hiperplasia fibrosa & $2(0,8)$ \\
Leucoplasia pilosa & $1(0,4)$ \\
TOTAL & $\mathbf{2 5 1 ( 1 0 0 )}$ \\
\hline
\end{tabular}

Fuente: Moret Y, González JM, Benavides I, Henríquez Y, Lárez L, Moreno S. Prevalencia de lesiones en la mucosa bucal en pacientes embarazadas que acuden al servicio de odontología de la maternidad Concepción Palacios durante el periodo Enero-Julio 2003. Acta Odont Venez. 2009; 47 (3). 


\subsection{Patologías periodontales}

A nivel de la encía, el agrandamiento gingival relacionado con el embarazo puede ser marginal generalizado o presentarse como masas tumorales simples o múltiples, se dice que es el resultado del aumento de los niveles de progesterona y de su efecto sobre la microvascularización, alteración del metabolismo tisular, modificaciones del pH salival, disminución de la IgA provocan la hiperplásica. El granuloma piógeno o tumor del embarazo es también una lesión hiperplásica que ocurre en cualquier momento de la gestación, tiene predilección por el maxilar superior, se ubica en la encía interdental, y es una lesión reactiva que revierte posterior al parto; registra cifras de prevalencia del $5 \%$ en la población de gestantes. ${ }^{26,27}$

Otra patología gingival, la que más afecta la salud bucal de las gestantes, es la enfermedad periodontal, que se caracteriza por ser un proceso infeccioso que involucra las estructuras de soporte de los dientes, es decir, la encía, el ligamento periodontal y el tejido óseo; usualmente se manifiesta como gingivitis o periodontitis. La gingivitis es la inflamación de la encía que rodea el diente y la periodontitis implica la destrucción de la encía, el ligamento periodontal y el hueso alveolar. La presencia de esta patología se determina usualmente en los estudios epidemiológicos mediante el Índice Periodontal Comunitario de Necesidad de Tratamiento (IPCNT) ${ }^{28} \mathrm{La}$ gingivitis y los agrandamientos gingivales son trastornos frecuentes durante el embarazo, por lo cual algunos miembros de la profesión médica consideran como normal que las encías sangren y se agranden. La inflamación gingival alcanza prevalencias entre el 50\% y el 98,3\%, algunos estudios muestran una frecuencia de afección hasta en el 100\% de las gestantes evaluadas. La periodontitis crónica leve, moderada y severa se evidencia respectivamente en el $29,7 \%, 18,4 \%$ y $0,5 \%$ de las mujeres, durante este periodo. Otro aspecto importante de las relaciones enfermedad periodontal y embarazo es que algunos autores han observado un incremento en la movilidad de los dientes durante la gestación asociado a la periodontitis. . $12,26,27,29^{2}$

Es evidente que la lesión bucal más frecuentemente relacionada con el embarazo es la enfermedad periodontal, esto como resultado del cambio hormonal pero también asociado a la presencia de irritantes locales; la evidencia parece indicar que el mayor número de eventos gingivales se registra en el segundo trimestre de embarazo. La literatura científica a nivel mundial asocia las enfermedades y condiciones periodontales inflamatorias durante el embarazo con eventos relacionadas al estado de gravidez como la eclampsia, preclampsia, la diabe- tes gestacional, el parto pretérmino, el bajo peso al nacer, por lo cual es importante analizar estos aspectos en forma detallada. ${ }^{30}$

\section{LA CONDICIÓN PERIODONTAL Y SU EFECTO SOBRE LA SALUD GENERAL DE LA GESTANTE $Y$ EL FETO}

El efecto que la condición oral puede tener sobre el organismo ha sido estudiado y a pesar de la controversia hay evidencia que la relaciona con el aumento del riesgo a presentar eventos cardiovasculares, con la descompensación en los niveles de glicemia en los pacientes diabéticos, con la diseminación hemática de infecciones a distancia, entre otras. De igual manera, el estado de salud general también tiene efecto sobre condición oral y se relaciona con el cáncer, la diabetes mellitus, y las alteraciones mentales, por mencionar algunas; por ello es importante que los profesionales de la salud y en particular los odontólogos implementen acciones orientadas a la prevención de las enfermedades orales y en particular de las periodontales. ${ }^{31}$ Adicionalmente, es importante resaltar que las infecciones dentales y las periodontales en particular, podrían comprometer sistémicamente a la gestante y poner en riesgo su vida, la del feto y la del recién nacido pues la literatura científica parece indicar que su presencia se asocia con preclampsia, parto pretérmino (PPT), bajo peso al nacer (BPN), restricción del crecimiento intrauterino (RCIU), aborto y diabetes gestacional (DG). Evidencias de esta relación se describe a continuación:

Aborto tardío (AT): Moore y colaboradores lograron establecer en su estudio que la enfermedad periodontal se correlacionaba con $\mathrm{AT}^{32}$ aspecto que también se insinúa en el trabajo de Michalowickcz y colaboradores. ${ }^{33}$ Sin embargo en la literatura revisada no se evidenció un modelo que permita analizar por las potenciales variables de confusión. ${ }^{32-34}$

parto pretérmino (PPT) y bajo peso al nacer (BPN): la relación de la enfermedad periodontal con el PPT y BPN se asocia con la presencia de mediadores inflamatorios en el torrente sanguíneo, aunque existe controversia al respecto (Tabla 2). La infección en general y, en particular la periodontal ocupa un lugar significativo en el desarrollo tanto del AT como del PPT y BPN aunque la fisiopatología no es del todo clara. La evidencia sugiere que es un proceso mediado por la producción local de citoquinas y prostaglandinas liberadas por la decidua y membranas fetales ante la exposición a bacterias y sus bioproductos. ${ }^{29}$ Hasta el momento no se ha podido explicar o probar los mecanismos exactos de cómo pudiera ocurrir un efecto sumatorio de las citocinas y de otros complejos con capacidad proinfla- 
matoria, generados en los tejidos periodontales que crean estrés oxidativo y metabólico. ${ }^{30}$ López-Arranz y Martínez, por su parte, afirman que la etiología del parto prematuro es multifactorial, existe evidencia que implica a factores infecciosos como posible causa en el $40 \%$ de los casos; ${ }^{34}$ sin embargo, la revisión de la literatura no permite dilucidar cuánto de esto se le podrían atribuir a infecciones orales de forma específica.

El mecanismo patogénico que, se cree, causa alteraciones en el binomio gestante-feto que puede estimular el trabajo del parto pretérmino, ocurre a través de una serie de mediadores proinflamatorios como las citoquinas, factores de crecimiento y productos bacterianos como: la fosfolipasa A2, las enzimas MMP-1, MMP-2, MMP-9 y MMP-7, o ciertas endotoxinas. La fosfolipasa A2 juega un papel importante en el inicio y mantenimiento del trabajo del parto al ser precursor de la síntesis de prostaglandinas. Por otro lado, las MMP sintetizadas por las bacterias son capaces de degradar la matriz extracelular, por lo que se las ha implicado en la rotura de las membranas fetales de forma prematura dando lugar a un parto pretérmino, bien directamente, o a través de la activación de otras MMPs u otras moléculas como citoquinas, o el factor de necrosis tumoral; ${ }^{33}$ es importante enfatizar sin embargo que aun hay aspectos que precisan ser investigados dadas las potenciales inconsistencias que existen sobre el tema (Tabla 2).

La preclampsia contribuye con el $42 \%$ de la mortalidad materna y perinatal y es la primera causa de restricción del crecimiento intrauterino, parto pretérmino y bajo peso al nacer. En el embarazo hay un estado fisiológico inflamatorio que se acentúa en las gestantes que desarrollan preclampsia y se asocia a un incremento en los niveles de citoquinas proinflamatorias (IL-6,TNF- $\alpha$, proteína $C$ reactiva) e infecciones incluyendo la periodontitis. Se observa ateroesclerosis a nivel placentario en mujeres embarazadas con preeclampsia así como también migración de bacterias patógenas orales a la placenta. Las patologías periodontales se relacionan con el incremento de la proteína $C$ reactiva en las mujeres con preclampsia; sin embargo este marcador es generalizado para todas las infecciones, no sólo para las de origen oral ${ }^{35}$ (Tabla 3).

La diabetes gestacional (DG) se define como la intolerancia a los carbohidratos que se detecta por primera vez durante el embarazo; está asociada con un incremento significativo del riesgo a morbilidad materna e infantil, incluyendo macrosomía, preeclampsia, parto pretérmino. Un ensayo clínico controlado aleatorizado sugiere que el tratamiento de la DG reduce la mortalidad y la morbilidad perinatal (Tabla 4).
Salud neonatal: Jared y colaboradores sugieren que la exposición In utero a patógenos orales incrementa el riesgo a ingresar a Unidades de Cuidados Intensivos (UCI) $;^{36}$ afirma además que las intervenciones que interrumpan la exposición fetal reduce el riesgo. La razón de esto podría sustentarse en el hecho que migración de bacterias patógenas orales a la placenta podría desencadenar eventos adversos además de la relación con la liberación de mediadores inflamatorios a parto pretérmino y bajo peso al nacer. Este autor encontró en su estudio que $6.9 \%$ de los recién nacidos fueron admitidos en las UCI, la mayor proporción eran seropositivos a patógenos orales comparado con los seronegativos ( $11 \%$ versus $5 \%$; $\mathrm{P}=$ 0.0019).

Los cambios bucodentales que registran las gestantes, la evidencia relacionada con su condición bucal y las potenciales implicaciones sobre la salud y la vida de la mujer en estado de gestación, el feto y el recién nacido ilustran sobre la necesidad de brindarle las mejores alternativas de atención odontológicas a las embarazadas por lo cual es importante analizar este aspecto.

\section{LA ATENCIÓN ODONTOLÓGICA EN LAS MUJERES EMBARAZADAS}

\subsection{La atención en salud}

La atención en salud hace referencia al cuidado que los profesionales del área les brindan a las personas y se puede analizar desde diferentes perspectivas. Desde la visión ética y de los dilemas que enfrentan la atención; desde la óptica económica y administrativa y de la disyuntivas que generan los marcos legales vigentes como la ley 100/93 y la constitución política de 1991 que propende por derechos individuales y deja de lado los derechos colectivos..$^{37}$ La atención en salud también se analiza desde la perspectiva de las reformas que tienden a privatizar los sistemas de salud y del papel secundario que asume el estado, aspectos que han afectado diversos ámbitos de la atención en salud incluyendo el proceso de formación profesional y su relación con la prestación de los servicios. $^{38}$

Otros analizan la atención en términos de la organización y articulación de los diversos recursos fisicos, tecnológicos y humanos disponibles para enfrentar y resolver los problemas de salud de una colectividad o desde la perspectiva de la funcionalidad del sistema de cuidado en salud;, ${ }^{39,40}$ también se aborda desde la percepción que tienen tanto los usuarios como los prestadores frente a la atención en salud que reciben u ofrecen analizando ya sea la satisfacción de los pacientes o los conflictos entre el deber ser y el hacer que enfrentan los profesionales que los atienden. ${ }^{41}$ 
Tabla 2. Asociación enfermedad periodontal con el BPN y parto pretérmino (PPT)

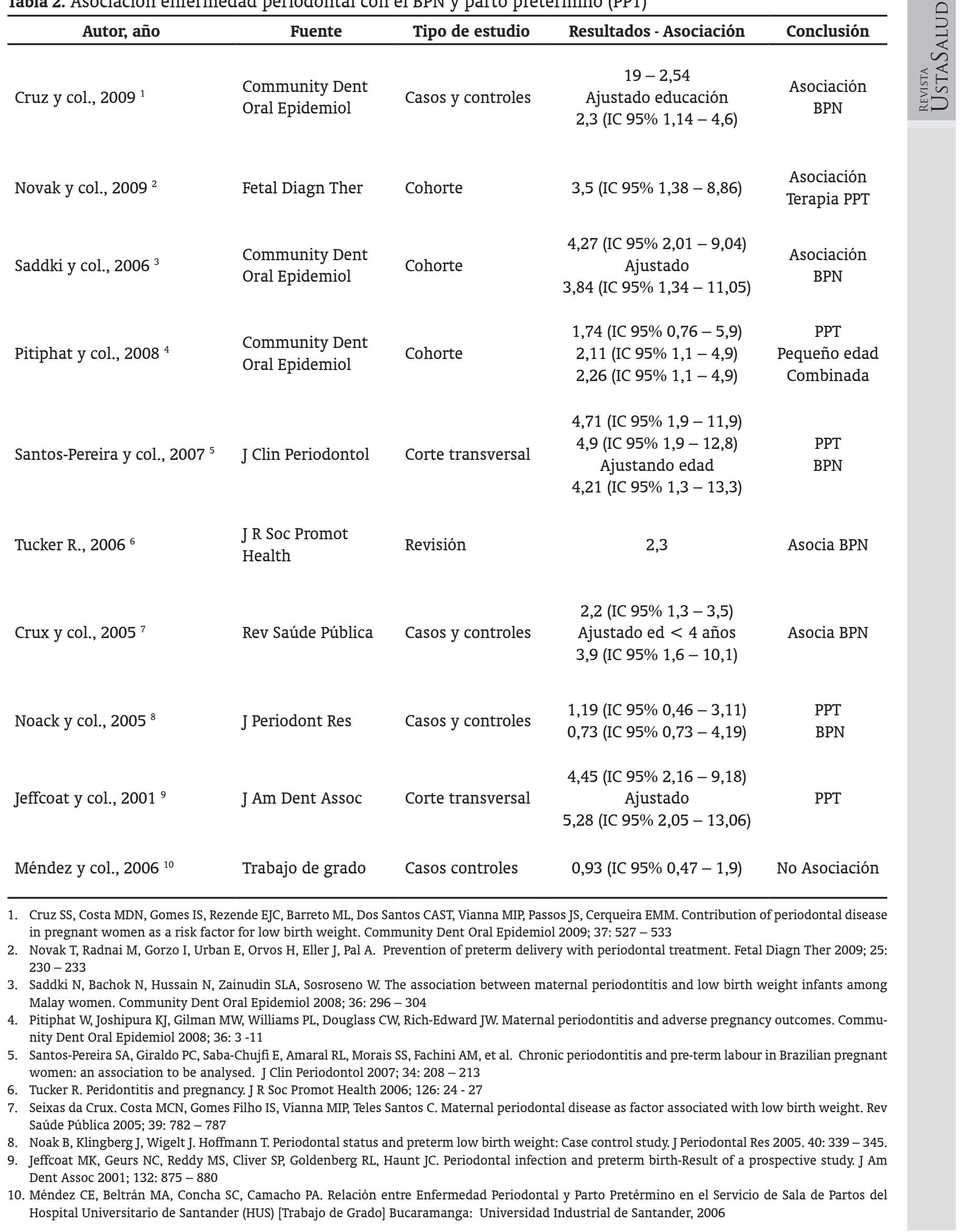


ARTÍCULO DE REVISIÓN

Tabla 3. Asociación enfermedad periodontal con preclampsia

\begin{tabular}{|c|c|c|c|c|}
\hline Autor, año & Fuente & Tipo de estudio & Resultados, Asociación & Conclusión \\
\hline Shetty y col., $2010^{1}$ & $\begin{array}{l}\text { Acta Obstet } \\
\text { Gynecol Scand }\end{array}$ & Corte transversal & 5,8 (IC 95\% 2,4 - 13,9) & Asociación \\
\hline Contreras y col., $2006^{2}$ & J Periodontol & Casos y controles & 3,0 (IC 95\% 1,9 - 4,9) & Asociación \\
\hline Boggess y col., $2003^{3}$ & Obstet Gynecol & Cohorte & 2,4 (IC 95\% 1,1 - 5,3) & Asociación \\
\hline Castaldi y col., $2006^{4}$ & $\begin{array}{l}\text { Rev Panam } \\
\text { Salud }\end{array}$ & Cohorte & 0,99 (IC 95\% 0,7 - 1,4) & No asociación \\
\hline
\end{tabular}

1. Sketch M, Shetty PK, Ramesh A, Thomas B, Prabhu S, Rao A. Periodontal disease in pregnancy is a risk factor for preeclampsia. Acta Obstet Gynecol Scand 2010; 89: $718-721$

2. Contreras A, Herrera JA, Soto JE. Arce RM, Jaramillo A, Botero JE. Periodontitis is associated with preeclampsia in pregnant women. J Periodontol 2006; 77: $182-188$

3. Boggess KA, Lieff S, Murtha AP, Moss K, Beck J, Offenbacher S. Maternal periodontal disease is associated with an increased risk for preeclampsia. Obstet Gynecol 2003; 101: 227 - 231

4. Castaldi JL, Bertin MS, Giménez F, Lede R. Enfermedad periodontal: ¿es factor de riesgo para parto pretérmino, bajo peso al nacer o preeclampsia? Rev Panam de Salud Publica 2006; 19: 253 - 258

Tabla 4. Asociación enfermedad periodontal con diabetes gestacional

\begin{tabular}{ccccc}
\hline \multicolumn{1}{c}{ Autor, año } & Fuente & Tipo de estudio & Resultados, Asociación & Conclusión \\
\hline Xing y col., $2006^{1}$ & $\begin{array}{l}\text { Am J Obstet } \\
\text { Gynecol }\end{array}$ & Corte transversal & $9,1($ IC95\% 1,1- 79,4) & Asociación \\
Dasanayake y col., $2008^{2}$ & J Dent Res & Corte transversal & $1,71($ IC 95\% 0,5 - 5,4) & No asociación
\end{tabular}

1. Xiong X, Buekens P, Vastardis S, Pridjian G. Periodontal disease and gestational diabetes mellitus. Am J Obstet Gynecol 2006; $195: 1086$ - 1089

2. Dasanayake AP, Chhun N, Tanner ACR, Craig RG, Lee MJ, Moore AF, Norman RG. Periodontal pathogens and gestational diabetes mellitus. J Dent Res 2008; 87: 328 - 333

La atención además se analiza desde la calidad, en términos de la provisión de servicios de salud a los usuarios individuales y colectivos de manera accesible y equitativa, a través de un nivel profesional óptimo, teniendo en cuenta el balance entre beneficios, riesgos y costos, con el propósito de lograr la adhesión y satisfacción de dichos usuarios. Sin embargo, la calidad de la atención tiende a definirse a la luz de las normas técnicas del proveedor y de las expectativas del paciente, tomando en consideración el contexto local. ${ }^{42}$ En Colombia de acuerdo al Decreto 1011 de 2006, en el que se establece el Sistema Obligatorio de Garantía de Calidad de la Atención de Salud en el marco del Sistema General de Seguridad Social en Salud, se define la atención de salud como el conjunto de servicios que se prestan al usuario en el marco de los procesos propios del aseguramiento, así como de las actividades, procedimientos e intervenciones asistenciales en las fases de promoción y prevención, diagnóstico, tratamiento y rehabilitación que se prestan a toda la población. ${ }^{43}$

Los sistemas de salud, otra alternativa para el análisis de la atención en salud, se definen como organizaciones que integran el ejercicio de los diversos trabajadores de la salud y su valoración social varía a lo largo de la historia, del lugar y del enfoque que se utilice para abordarlos. Durante casi todo el siglo XX el hospital y su marco médico ocupó una posición central en la organización del sistema de salud y hablar de atención en salud se restringía a discutir cómo organizar el personal médico dando énfasis a los fenómenos biológicos para orientar la prestación de la atención en salud. Posteriormente surge el modelo liberal privatizador que implica que la atención en salud es regulado por el sistema estatal pero involucra la compra y venta de servicios a las empresas de salud dentro de un sistema de mercado. ${ }^{44}$ Cualquiera de los abordajes planteados se enfocan desde mirada reduccionista y funcional que no priorizan sobre las verdaderas necesidades de las personas. En este sentido, las diferencias en los conceptos planteados, la falta de integración en los aspectos considerados en cada uno de ellos, parecen orientar la necesidad de formular nuevas bases que permitan redefinir el concepto de atención y esto es prioritario cuando se habla de la atención de la salud de las gestantes y por ende del feto o el recién nacido. 


\subsection{La atención en salud de las gestantes}

La atención en salud de las gestantes (ASG) definida como las acciones implementadas por los profesionales del campo, dirigidas a monitorear el proceso del embarazo con el fin de promover la salud y prevenir cualquier tipo de complicación tanto para la mujer embarazada como la del feto. La ASG podría analizarse de dos maneras: la primera hace alusión al momento en que la mujer es abordada con el propósito de orientar sus cuidados gestacionales en salud y la segunda refiere a la base conceptual que orienta los programas dirigidos a las mujeres embarazadas.

Referir el momento es retomar de la literatura los conceptos relacionados con el cuidado pregestacional y el cuidado prenatal. El cuidado pregestacional (CPG) refiere a la necesidad de proveer una atención profesional continua del proceso de gestación que debe iniciar antes de la concepción e involucra tanto a las mujeres como a los hombres y que busca una aproximación tanto del bienestar físico como emocional en el periodo fértil del ciclo vital de las personas.$^{45}$ Implica hablar de embarazo y contracepción a las personas jóvenes, dialogar con la pareja que planea tener hijos de todos los aspectos de la atención, de los efectos del embarazo en la madre, de los requerimientos para lograr un embarazo en las mejores condiciones; es frecuente que el CPG esté orientado más a grupos de riesgo y dirigido probablemente a evitar que las personas en estas condiciones se embaracen. ${ }^{46}$ Whitworth y Dowswell sustentan el valor del CPG en el hecho de que el tabaquismo, el consumo de alcohol, la nutrición deficiente y otros factores del estilo de vida (evitables), pueden dar lugar a resultados deficientes para las madres y los recién nacidos. La promoción sistemática de la salud (asesoramiento, educación y pruebas de detección) antes de la concepción puede promover cambios para mejorar la salud y puede ser una oportunidad para identificar factores de riesgo como la infección, que se puede tratar antes que comience el embarazo. En la revisión sistemática de las citadas investigadoras se muestra como las intervenciones de promoción de la salud estimulan a las mujeres a que tengan estilos de vida más sanos; pero concluyen que se necesitan más pruebas antes de poder recomendar su implementación generalizada. ${ }^{47}$

El cuidado prenatal (CPN) es un conjunto de acciones que involucra una serie de visitas por parte de la embarazada a la institución de salud y la respectiva consulta médica, con el objetivo de vigilar la evolución del embarazo, detectar tempranamente riesgos, prevenir complicaciones y prepararla para el parto, la maternidad y la crianza. La Organización Mundial de la Salud (OMS) considera que el cuidado materno es una prioridad que forma parte de las políticas públicas como estrategia para optimizar los resultados del embarazo y prevenir la mortalidad materna y perinatal. Entre los objetivos del CPN está diagnosticar las condiciones fetal y materna, identificar factores de riesgo y educar a la gestante para el ejercicio de la maternidad y la crianza. Además de los riesgos biológicos, se explora los riesgos biopsicosociales y se brinda orientación a la gestante y a su pareja para propiciar una relación óptima entre padres e hijos desde la gestación. ${ }^{48}$

La segunda forma de abordar el cuidado de la gestante se fundamenta en la base conceptual que orienta los programas dirigidos a las mujeres embarazadas. La revisión de la literatura parece mostrar que la atención de las gestantes se desarrolla con base en diferentes modelos de atención. Los relacionados con el enfoque de riesgo, ${ }^{49}$ los fundamentados en la Atención Primaria en Salud concebidos bajo la perspectiva de lograr intervenciones que promuevan asistencia sanitaria esencial basada en métodos y tecnologías prácticas, científicamente fundadas y socialmente aceptables, puesta al alcance de todos los individuos y familias de la comunidad mediante su plena participación y a un costo que la comunidad y el país puedan soportar, en todas y cada una de las etapas de su desarrollo con un espíritu de autorresponsabilidad y autodeterminación..$^{50}$ Los que retoman la propuesta de Mains de las tres demoras de la mortalidad materna, convertidas en oportunidades (promoción de la salud de la familia gestante, acceso a la atención de la familia de la gestante y calidad de la atención de la gestante y su hijo). ${ }^{51}$ El enfoque de la promoción de la salud propone un marco para establecer intervenciones con individuos, familias y comunidades con el fin de mejorar la salud materna y neonatal, ${ }^{52}$ y si bien cada uno ellos tiene un componente ontológico que los hace diferentes en términos prácticos todos parecen abordar la atención de las gestantes desde la perspectiva asistencialista, biomédica y fraccionada.

Adicionalmente, la mayoría de modelos de CPN no han sido sometidos a una evaluación científica rigurosa, Cáceres-Manrique y Pécora y colaboradores afirman que los modelos han sido deficientes en términos de oportunidad, calidad, con consultas irregulares, larga espera y mala respuesta en el cuidado de las mujeres. ${ }^{48,53}$ A partir de los hallazgos sobre asociación entre mortalidad evitable en la infancia y calidad del CPN, se recomienda revisar la calidad de la atención en las instituciones que prestan servicios de salud a la población materno-infantil; además, la evidencia no permite identificar estrategias exitosas, pero si errores en las acciones en la atención de las gestantes. ${ }^{48,53,54}$ 
Es evidente que tanto para el CPG como para el CPN es necesario un equipo multidisciplinario, con visión integradora que trasciendan la mirada fraccionada y que reconozcan a la mujer embarazada desde la perspectiva biopsicosocial inmersa en un contexto político, económico, cultura y físico que determina en gran medida los comportamientos de adherencia y cuidado de la gestante. Sin embargo son pocos los modelos que ofrecen atención a las gestantes que abordan la atención promocional o de prevención primaria, secundaria o terciaria con una visión holística y que incluyan la atención de la condición oral en la etapa preconcepcional o durante de la gestación como un estrategia orientada a mejorar las condiciones de vida y salud para la gestante y su hijo, y que va en contravía con la evidencia que sobre la relación de la condición oral con la salud de la gestante existe en la actualidad.

\subsection{La atención odontológica de las gestantes}

La atención odontológica de las embarazadas define los servicios de promoción de la salud, prevención de las enfermedades orales en todos sus niveles y de asistencia curativa que se ofrecen a las mujeres durante etapa preconcepcional o en la gestación; si bien se han establecido ciertas pautas que orientan al profesional en aspectos como la radiación tolerada para la toma de radiografias dentales, con respecto a la posición con la que se puede atender a la gestante, el momento propicio para atención, la medicación y los anestésicos que se le puede suministrar. ${ }^{55}$

Sin embargo, no es clara en la literatura las normas técnicas y administrativas que en Colombia determinan la atención de las mujeres en este periodo, pues todo parece restringirse a los establecido inicialmente en la resolución 412 del 2000 y posteriormente en las guías de promoción de la salud y prevención de enfermedades en la salud pública, que parecen insuficiente para brindar una visión integral de las mujeres gestantes y sus necesidades generales y orales. En adición a esto, es necesario reconocer el predominio en los procesos de atención dental de las embarazadas desde una visión asistencialista, biomédica y fraccionada similar a lo observado para el CPN sin ofrecer una visión clara de la multiplicidad de aspectos que pueden llegar a influenciar la atención o la asistencia odontológica de las mujeres durante su gestación. ${ }^{56.57}$

\section{ASPECTOS QUE INFLUENCIAN LA ATENCIÓN ODONTOLÓGICA DE LAS GESTANTES}

En este aparte se describe lo reportado en la literatura con respecto a los aspectos relacionados con las gestantes y los odontólogos, la familia, los de- terminantes sociales, la cultura, el sistema de salud, las políticas, la infraestructura y el ambiente frente la asistencia y a la atención odontológica; sin embargo, es importante anotar que no es fácil discriminar por cada uno de ellos pues parecen estar estrechamente relacionados.

\subsection{Aspectos relacionados con las gestantes}

Este es quizás uno de los aspectos más frecuentemente abordados en las investigaciones relacionados con la atención de las gestantes; los temas aluden en particular las creencias, los mitos y las opiniones de las mujeres embarazadas con respecto a su estado, su relación con la salud bucal, y la atención odontológica; también exploran las representaciones que sobre la salud y enfermedad oral tienen las gestantes; las barreras que las embarazadas perciben frente a su atención; además, la relación de la salud oral de la gestante con su calidad de vida.

Callejo y colaboradores reportan cómo durante años la comunidad médica y odontológica se ha visto envuelta entre mitos, creencias y costumbres sobre todo en el periodo gestacional de la mujer y reporta que estos aspectos generan incógnitas en el ámbito de la atención odontológica de las gestantes. ${ }^{58}$ No existe un consenso general con respecto a las creencias; aunque algunos autores reportan que las gestantes rechazan la atención odontológica como producto del potencial daño de este procedimiento para la salud del feto en desarrollo, otros muestran cómo esto no es percibido por el grupo de gestantes evaluados por ellos. ${ }^{59,60}$

Adicionalmente se observa que a pesar de la evidencia que el embarazo per se no es factor causal para el desarrollo de caries, parece que las gestantes si creen esta relación existe; diferentes autores han señalado que las personas esperan la pérdida de piezas dentales durante el embarazo; esta creencia es más frecuente en las mujeres de bajos recursos, del área rural y con bajos niveles educación y los autores atribuyen esto a un mito que se traspasa generacionalmente. ${ }^{58}$

De acuerdo con lo reportado por Rengifo, adicional a los factores de riesgo, que pueden asociarse con la condición oral de las gestantes, como: el estrato socioeconómico, la dificultad de acceso a los servicios asistenciales, la baja escolaridad, los hábitos, se encuentran las creencias y las motivaciones de cada individuo. En la gestación estas creencias pueden llegar a ser muy representativas e influyentes en el desarrollo de la condición oral ligadas a la percepción de susceptibilidad, severidad y beneficios que posee cada gestante, como se plantea en el modelo de creencias. Adicionalmente, se concibe que toda creencia se desarrolla, transmite y mantiene a tra- 
vés de la experiencia del grupo social que la práctica, por lo cual las creencias durante el embarazo se ven fuertemente influenciadas por el contexto de familia (abuela-madre-gestante) y el contexto el social (gestante-gestante), en el cual el individuo está inserto, la información que se toma del contexto es comprendida y aprehendida de acuerdo a las características de cada persona. ${ }^{21}$

Escobar y colaboradores refieren cómo la función social de la maternidad parece estar estrechamente relacionada con la salud, pero afirman que es necesario comprender que la gestación y la maternidad constituyen acontecimientos trascendentales en la vida de una mujer caracterizados por sentimientos múltiples y en ocasiones contradictorios, de este modo la salud bucal no es una preocupación central en la embarazada; ${ }^{8}$ aspecto que parece coincidir con lo reportado por Miraschi y colaboradores quienes en su estudio muestran cómo a pesar de los problemas de salud oral evidenciados en las gestantes evaluadas, éstas no parecen percibir que influyan en gran medida en su calidad de vida.$^{59}$ Saddki y colaboradores por su parte afirman que las madres registran una actitud muy pobre hacia al cuidado oral y por esto es necesario orientar esta situación ya que las enfermedades orales no tienen manifestaciones notorias por lo cual las gestantes no perciben la necesidad de asistir consulta odontológica. ${ }^{60}$

Saldarriaga y colaboradores postulan en su estudio que la principal representación que hacen las gestantes con relación a la "salud bucal" es "no tener caries" y coincide con lo que en el ENSAB III presenta. ${ }^{24,61,62}$ Según estos autores las gestantes evaluadas por ellos, atribuyen como principal causa de caries "no cepillarse o cepillarse mal los dientes", "consumo de dulces", "descalcificación" y "mala alimentación"; sin embargo, en sus resultados evidencian que el antiguo mito de que "en cada embarazo se pierde un diente" no tiene tanta vigencia en la actualidad; además indican que el $57,1 \%$ de las gestantes de su estudio no considera el embarazo como un momento de riesgo para desarrollar enfermedades orales; por lo cual, podrían pasar por alto las visitas preventivas al odontólogo, cuando en realidad son un grupo de alto riesgo pues en ella confluyen aspectos relacionados con el cambio metabólico, las alteraciones psicológicas y del comportamiento que las llevan a descuidar las prácticas de higiene oral. Las mujeres que relacionan el embarazo con riesgo bucodental se lo atribuyen a la "descalcificación de los tejidos" desconociendo los verdaderos factores asociados a las patologías bucodentales. También muestran cómo cerca del 55\% de las gestantes no consultó al odontólogo a pesar de las molestias que sentían; por no darle importancia o por falta de tiempo; y el 11\% reportó temor a asistir a la consulta odontológica. Saddki y colaboradores por su parte ilustran cómo el temor al dolor y la ansiedad tienen impacto en el comportamiento de uso de cuidado dental. ${ }^{60}$

Marc y colaboradores refieren como la asistencia a la consulta por parte de las gestantes oscila entre $30 \%$ y $36 \%$; 63 aunque, la literatura reporta una amplia variación de los resultados entre los diferentes países, pues podrían estar entre $27 \%$ y $64 \%$ mientras que Saddki y colaboradores refieren que está entre $23 \%$ y $37 \% \%^{60}$ sobre esto es importante anotar que, la asistencia a la consulta no significa que a las gestantes se les haya resuelto sus necesidades bucodentales, ni que se les efectúe un seguimiento adecuado coherente con sus condiciones orales. Estos autores destacan además, cómo las mujeres en gestación no perciben el sangrado gingival como un signo de inflamación o por lo menos no es un problema por cual deban solicitar atención odontológica; valga la aclaración que la hemorragia gingival no es fenómeno normal del embarazo, como algunas gestantes creen, y está relacionado con la gingivitis y periodontitis, patologías que parecen asociarse con complicaciones perinatales. Reportan además, cómo el aspecto económico puede desincentivar la asistencia a la consulta de las mujeres embarazadas con frecuencias reportadas por esta causa con intervalos entre $18 \%$ y el $27 \% .^{59,62}$

Córdova y Bulnes indican a partir de su investigación cómo el $66 \%$ de las gestantes tiene un nivel de conocimiento sobre prevención de la salud oral que cataloga como regular; a pesar de esto, hay estudios donde se encontró que el $72 \%$ de las embarazadas tiene buen conocimiento producto de su propia experiencia. Refieren además, cómo aproximadamente el $60 \%$ de las mujeres en etapa de gestación posee un regular conocimiento con respecto a aspectos relacionados con la consulta odontológica. Reseñan también, cómo el nivel de conocimiento en salud oral está estrechamente relacionado con el nivel académico alcanzado. ${ }^{64}$

\subsection{Aspectos relacionados con los profesio- nales de la salud que las atienden}

Algunos autores han señalado que las actitudes y conductas de la población ante el proceso saludenfermedad son influenciados por la cultura médica existente. En ocasiones las gestantes se niegan asistir a la consulta cuando perciben falta de capacidad técnica y esto aunado a los costos que genera la atención influye en la baja demanda de atención odontológica. ${ }^{65}$ 
Escobar y colaboradores establecen que con el discurso de los odontólogos centrado en explicaciones de tipo biológico y de responsabilidades individuales asociadas con "hábitos poco saludables", se limitan a formular advertencias que pueden llevar a la "culpabilización" del paciente y a desconocer los múltiples condicionantes del proceso salud enfermedad bucodental; esto aunado a la gran responsabilidad que se le delega a la mujer gestante hace que ella reclame apoyo con el propósito de compartir responsabilidades con el profesional respondiendo también a la lógica biomédica en la que los servicios de salud son la única alternativa para tener una buena salud oral. Los odontólogos están inmersos en un orden simbólico construido bajo la filosofía occidental y la práctica odontológica tradicional se fundamenta en el dominio que la reduce a conocimientos biotécnicos y con frecuencia desconocen el sujeto, su carácter social, producto del proceso educativo de formación profesional. ${ }^{8}$

Por otra parte, Romero concluye en su trabajo de investigación que aunque los profesionales de la salud oral conocen que la salud bucal forma parte de la salud general, poco hacen realmente para promocionarla; lo que determina, la necesidad de modificar los planes de estudio a nivel de las facultades y de incorporar una orientación pluriparadigmática desde la perspectiva de las ciencias naturales y sociales desde una perspectiva ecobiopsicosocial. ${ }^{66}$ Otros escritos reportan como el temor de los odontólogos o la falta de entrenamiento se convierten en determinantes para limitar la atención a las gestantes. ${ }^{55,67}$

El médico es un recurso valioso en la promoción de la salud y prevención de las enfermedades orales en las maternas, detectar las patologías orales más frecuentes y de esta forma orientar y remitir la gestante al odontólogo. Sin embargo, hay diferentes investigaciones que ilustran como la frecuencia de remisión es muy variable pues oscilando entre el $23 \%$ y el $80 \% .{ }^{61}$ Otras investigaciones exponen que si el ginecólogo remite a la mujer en estado de gravidez al odontólogo se alcanzan coberturas para brindar atención primaria en el $100 \%$ de mujeres (68). Otros afirman que los profesionales de la salud no tenían certeza respecto a la etapa más adecuada para la atención odontológica de las gestantes o que debería atenderse durante el segundo trimestre y por ello algunas maternas perciben que hay demora en la remisión. ${ }^{69}$

\subsection{Los determinantes sociales de la atención odontológica de las gestantes}

Saddki y colaboradores reportan que una pobre condición socioeconómica, es un bajo nivel educa- tivo, desempleo y bajo ingresos en el hogar son factores importantes asociados con una menor probabilidad de visitar el odontólogo durante el embarazo. ${ }^{60}$ Por otra parte, Thomas reporta cómo la falta de conocimiento acerca de la salud bucodental está fuertemente relacionada con mujeres de bajo nivel educativo y bajos niveles socioeconómicos. ${ }^{70}$

La influencia de los aspectos sociales es analizada por Casals cuando retoma lo descrito por Julián Tudor-Hard quien expresaba como el uso de los servicios de sanitarios es más eficiente entre aquellas personas con menor necesidad que entre las que tienen una mayor necesidad. Las investigaciones han demostrado además, cómo los odontólogos se establecen preferentemente en la mejores áreas socioeconómicas. ${ }^{71}$

En Colombia, la investigación muestra cómo el acceso al tratamiento odontológico es restringido y la gran mayoría de las gestantes que pertenecen a poblaciones vulnerables tienen poco acceso a los servicios de salud. ${ }^{72}$

\subsection{El sistema de salud y las políticas relacio- nadas con la atención odontológica de las mujeres embarazadas}

Al referirse a los sistemas de atención odontológica Couto y colaboradores reportan cómo esta asistencia es de escasa cobertura, con un modelo prevalente de servicio que actúa frente a la demanda, con abordaje curativo; pocas actividades preventivas, de alto costo, concentración de los servicios en las ciudades con la consecuente desasistencia del medio rural, ausencia de trabajo en equipo y escaso mantenimiento a equipo e infraestructura. ${ }^{73}$ Para Saddki y colaboradores la calidad de la atención es un componente esencial del cuidado en salud, pues esto afecta el uso de los servicios, la adherencia al tratamiento, y está también asociado con el estatus de salud y sus resultados. Los excesivos tiempos de espera, las demoras y retardos en la atención dan como resultado pacientes insatisfechos. La concentración de odontólogos en ciertos servicios, áreas o regiones. ${ }^{60}$

Ayala de la Vega encontró que en los centros de salud, otros profesionales de la salud que trabajan directamente con las gestantes consideran importante el trabajo del odontólogo recomendado a las gestantes la atención del servicio dental; sin embargo no existe seguimiento para verificar si efectivamente se realiza la atención, quedando la asistencia a criterio de la gestante; en otras investigaciones sin embargo se percibe poco interés de otros profesionales por la salud bucodental de 
las mujeres embarazadas pues el $56 \%$ no revisa su boca, $53 \%$ considera innecesario remitirla. ${ }^{69}$

Los antecedentes de las políticas en salud bucal en Colombia están determinados por los cambios que ha sufrido el sistema de atención a la salud. Antes de 1993 y bajo la organización del Sistema Nacional de Salud, con una dirección centralizada en el Ministerio de Salud, la política de salud bucal giró en torno a una concepción preventivista que centró sus esfuerzos en las acciones educativas y de utilización del flúor dirigidas especialmente a los escolares; en este periodo también se priorizó la atención de las mujeres gestantes a partir de su captación en los programas de control prenatal. El Programa Acción Preventiva Odontológica, se combinó con una política pública de fluoruración sistémica, inicialmente a través del agua y posteriormente y hasta la fecha, a través de la sal de consumo humano. Bajo el Sistema Nacional de Salud las coberturas de los servicios curativos fueron bajas y las de salud bucal en particular fueron muy bajas, no mayores del 4\%. En la década de los 90, con la implementación de la Ley 10 de 1990, la Ley 60 de 1993 y la Ley 100 de 1993 que reorganizó el Sistema General de Seguridad Social en Salud poco se logra avanzar en materia de fomentar la salud bucal para toda la población. ${ }^{74}$

En el marco de la Ley 100 de 1993 en el campo de la salud bucal, el Plan de Atención Básica $\mathrm{PAB}$-, recomendaba, pero no reglamenta, a los entes territoriales incluir contenidos educativos y de promoción de la salud bucal en la estrategia de escuelas y municipios saludables; quedando a discreción de cada municipio, si se implementa y las metodologías empleadas. El Plan Obligatorio de Salud - POS - , establece a través del artículo 89 de la Resolución 5261 de 1994, las actividades, intervenciones y procedimientos de atención curativa en salud oral y a través de la Resolución 0412 de 2001, específicamente a través de la Norma Técnica Preventiva de Atención en Salud Oral y de la Norma Técnica de Crecimiento y Desarrollo para el menor de diez años, las actividades para la atención preventiva. Entre otras actividades, estas normas técnicas incluyen: la educación a los padres para la higiene de la boca en la etapa de erupción dentaria y el fomento de la lactancia materna; el control y remoción de placa, la aplicación de flúor y sellantes y el detartraje supragingival. Después de 1994, se han expedido varias resoluciones y circulares que trazan o ajustan los lineamientos para el PAB y el POS, pero todas dentro del mismo marco lógico orientado a la intervención sustentados en factores de riesgo y con una perspectiva más individual que de tipo comunitario. ${ }^{74}$
Desde el 2000, se advierte que en la reglamentación de los planes y programas del Sistema General de Seguridad Social en Salud se excluyó paulatinamente la salud bucal, no figura en el PAB y por lo tanto, en la gran mayoría de los entes territoriales no se asumió como una prioridad y en muchos municipios los programas escolares de salud bucal se suspendieron o no contaban con los recursos necesarios. Otros aspectos relevantes del contexto nacional por su impacto sobre la salud pública bucal son: la dificultad de acceso a los servicios aunque no se hace referencia específica a los servicios de salud bucal; las deficiencias técnicas de documentos tan importantes como la Norma para la Atención Preventiva en Salud Bucal; los resultados inciertos de la estrategia de escuelas saludables; la falta de monitoreo continuo al uso de productos fluorurados por parte de la población, especialmente los niños; la falta de sistemas de información completos y rigurosos que faciliten el registro y seguimiento de las diferentes enfermedades bucales en las instituciones y en el Ministerio. ${ }^{74}$

A partir del 2007, La reforma de la Ley 100 de 1993 que se plasman en la Ley 1122 de 2007, la promulgación del decreto 3039 de 2007 por el que se adopta el Plan Nacional de Salud Pública-PNSP- y la resolución 425 de 2008 en la que se define la reglamentación para la implementación del PNSP en un contexto territorial representó una nuevo tropiezo para el desarrollo de la salud bucal pues, a pesar que la salud bucal y, en particular de la gestantes, surge como una prioridad dentro del PNSP la implementación de las acciones se delegan a decisiones de los entes territoriales. ${ }^{75-77}$

A pesar de los beneficios que podría generar un tratamiento bucal adecuado y oportuno, hay múltiples barreras y limitantes para promover la atención y la utilización de los servicios odontológicos de la mujer embarazada, por factores inherentes al sistema de salud y a las disposiciones legales que determinan los planes de acción y a la misma gestante. Además, los proveedores del cuidado en salud oral y prenatal evitan brindar atención bucodental durante el embarazo ya sea por falta de comprensión de las repercusiones sobre la salud, la seguridad de la madre y el niño y por las potenciales implicaciones legales que pueden derivarse. ${ }^{8,64}$

\subsection{Aspectos relacionados con las atención odontológica prestada en las instituciones, la infraestructura y con el ambiente}

Los problemas de accesibilidad a las instituciones que prestan la atención en salud se constituyen en factores importantes, pues se convierten en barreras para que las gestantes puedan acceder un 
servicio oportuno y de calidad. La accesibilidad se constituye en un aspecto crucial que promueve mejores condiciones de salud para las maternas, y para poder garantizarla es necesario eliminar todas las barreras que impiden a las mujeres embarazadas obtener unos servicios acorde con sus necesidades.

Barrios al retomar lo reportado por Mains analiza, cómo existen cuatro demoras básicas en la atención oportuna y adecuada de las gestantes y que podrían desencadenar la muerte: la primera relacionada con el poco conocimiento o reconocimiento de los signos que podrían representar amenaza para su vida y su salud por parte de la mujer. La segunda que hace alusión a las condiciones de inequidad de género que no les permiten asumir su derecho de decidir por sí misma en busca de una atención adecuada y oportuna. La tercera demora, expresa Barrios, está relacionada a las limitaciones por falta de vías de comunicación y medios de transporte.

Finalmente la cuarta demora, hace alusión a la atención deficiente e inoportuna, ya sea por falta de competencias de los proveedores de los servicios de salud o por la falta de suministros de insumos médico-quirúrgicos apropiados. ${ }^{78}$ En la literatura odontológica revisada no se encontraron artículos que refirieran a la infraestructura institucional y urbana, ni el estado climático como aspectos que influencian el acceso a los servicios dentales; sin embargo y de acuerdo a los planteamientos de Mains valdría la pena explorar estos aspectos como potenciales factores que podrían afectar la asistencia y la adherencia a la consulta odontológica por parte de la mujer gestante.

Con base en los cinco ejes desarrollados en este escrito se podría concluir que es necesario analizar los cambios biopsicosociales que registran las mujeres gestantes con una mirada integral que incentive una mejor comprensión por parte de los diferentes profesionales, que promueva una buena atención y una mejor calidad de vida. Las Patologías orales, en especial la enfermedad periodontal, se presentan con frecuencia en las mujeres embarazadas lo que ilustra la necesidad de una atención especial para ellas, en particular por los potenciales riesgos que estos eventos representan para la salud y la vida tanto de la madre como la de su hijo. En orden de ideas es importante reconocer la multiplicidad de aspectos que inciden en la salud y la atención odontológica de la materna todo con el propósito de actuar sobre ellos de forma efectiva.

\section{BIBLIOGRAFÍA}

1. Boggess KA, Maternal oral health in pregnancy. Obstetrics \& gynecology. 2008; 111: 976 - 986

2. Urbina CC, Villaseñor SJ. Trastornos mentales y el embarazo. Revista Digital Universitaria. 2005; 6(11). URL disponible en: http://www.revista.unam.mx/vol.6/num11/ art108/art108.htm

3. Isaza ODC, Reyes EL, Caviedes J. Consideraciones de la mujer embarazada en la consulta endodóntica. URL disponible en: http://www.javeriana.edu.co/academiapgendodoncia/art_revision/revision_2006/i_a_revision13.html

4. Suresh L, Radfar L. Pregnancy and lactation. Oral Surg Oral Med Oral Pathol Oral Radiol Endod 2004; 97 : 672 682

5. Fontaine Machado O, García Martínez A, Hernández Meléndez E, Castañeda Abascal I. Intervención psicológica en salud bucal en embarazadas. Psicología y Salud 2009; 19: 83 - 89

6. Vera-Delgado MV, Martínez Y, Pérez L, Fernández A, Mauradin A. Nivel de salud oral de la mujer embarazada de la comunidad autónoma de la región de Murcia. Odontología Preventiva 2010; 2: 1 - 7

7. Bastarrechea M, Fernández L, Martínez T. La embarazada y su atención estomatológico integral como grupo priorizado área de salud Moncada. Rev Cubana Estomatol 2009; 46: 59 - 68

8. Escobar G. Sosa C. Burgos LM. Representaciones sociales del proceso de salud enfermedad bucal en madres gestantes de Medellín, Colombia. Salud Pública de México 2010; 52: 46 - 51

9. Genolet A, Lera C, Gelsi C, Schonfeld Z, Musso S, Mulone MS, Schumck MS. La experiencia del embarazo en el tránsito de la adolescencia. Ciencia, Docencia y Tecnología 2004; 28 (XV): 51 - 94

10. Medina A, Mayca J. Creencias y costumbres relacionadas con el embarazo, parto y puerperio en comunidades nativas Awajun y Wampis. Rev Perú Med Exp Salud Pública 2006; 23: 22 - 27

11. Chávez RE, Arcaya MJ, García G, Surca TC, Infante MV. Rescatando el autocuidado de la salud durante el embarazo, el parto y al recién nacido: Representaciones sociales de mujeres de una comunidad nativa en Perú. Texto Contexto Enferm 2007; 16: 680 - 687

12. Gómez López ME, Aldana Cava E. Alteraciones psicológicas de la mujer con embarazo de alto riesgo. Psicología y Salud 2007; 17: 53 - 61

13. Garbero I. Salud oral en embarazadas: conocimientos y actitudes. 2005; Acta Odontol Venez 43 (2) [Fecha de acceso: abril de 2010]. URL disponible en: http://www. actaodontologica.com/ediciones/2005/2/salud_oral_embarazadas.asp

14. Fernández OM, Chávez MG. Atención odontológica en la mujer embarazada. Arch Inv Mat Inf 2010; 11: 80 - 84

15. Marín D, Bullones MA, Carmona FJ, Carretero MI, Moreno MA, Peñacoba $C$. Influencia de los factores psicológicos en el embarazo, parto y puerperio. Un estudio longitudinal. 2008 Nure Investigación, 37 [Fecha de acceso: abril de 2010]. URL disponible en: http://www. fuden.es/FICHEROS_ADMINISTRADOR/INV_NURE/proyemb37210200893951.pdf

16. Barclay RL, Barclay ML. Aspects of the normal psychology of pregnancy: the midtrimester. Am J Obstet Gynecol 1976; 125: 207 - 211 
17. Gotlib IH, Whiffen VE, Mount JH, Milne K; Cordy NI. Prevalence rates and demographic characteristics associated with depression in pregnancy and the postpartum. Journal of Consulting and Clinical Psychology 1989; 57: 269 - 274

18. Rodríguez HE, López M. El embarazo. Su relación con la salud bucal. Rev Cubana Estomatol 2003;48 (2). [Fecha de acceso: abril de 2010]. URL disponible en: http://bvs.sld. cu/revistas/est/vol40_2_03/est09203.htm

19. Montes-Muñoz MJ, Martorell Poveda MA, Jiménez Herrera MF, Verdura Anglada T, Burjalés Martí D. Representaciones del cuerpo en el embarazo. Experiencia de las mujeres. Matronas Prof 2009; 10: 5 - 10

20. Torres Gutiérrez, M. Impacto emocional del embarazo de alto riesgo. Revista Colombiana de Psiquiatría 2004; 23: $285-297$

21. Rengifo HA. Creencias acerca de la salud oral en gestantes en tres ciudades colombianas. Rev Fac Odontol Univ Antioq 2009; 20: 171 - 178

22. Marc JNC, Plutzer K, Plutzer k. Women attitudes and perceptions of oral health and dental care during pregnancy. J Perinat Med 2010; 38: 3 - 8

23. Vera-Delgado MV, Martínez Beneyto Y, Pérez L, Fernández A, Mauradin A. Nivel de salud oral de la mujer embarazada de la comunidad autónoma de la región de Murcia. Odontología Preventiva. 2010; 2: 1 - 7

24. Ministerio de Salud. Estudio Nacional de Salud BucalENSAB III. Bogotá, Colombia: MINSALUD, 1999. Tomo VII

25. Laffita YM, Riesgo YC, Corujo CM, Crespo MI. Salud bucal en gestantes de un área de salud urbana. MEDISAN; 2009; 13(4): (aprox. 4p) [Fecha de acceso: junio de 2010]. URL disponible en: http://bvs.sld.cu/revistas/san/vol13_4_09/ san07409.htm

26. Díaz Guzmán LM, Castellanos Súarez JL. Lesiones de la mucosa bucal y comportamiento de la enfermedad periodontal en embarazadas. Med Oral Patol Oral Cir Bucal 2004; 9: 430 - 437

27. Moret Y, González JM, Benavides I, Henríquez Y, Lárez L, Moreno S. Prevalencia de lesiones en la mucosa bucal en pacientes embarazadas que acuden al servicio de odontología de la maternidad Concepción Palacios durante el periodo Enero-Julio 2003. Acta Odont Venez [en línea] 2009; 47 (3) [Fecha de acceso: mayo de 2010]. URL disponible en: http://saber.ucv.ve/ojs/index.php/rev_aov/ article/view/390/354

28. Carrión Morraga C. Diagnóstico de salud oral de primigestas que acuden a control prenatal al consultorio Dr. José A. Astaburruaga, Universidad Talca 2004 [Fecha de acceso: junio de 2010]. URL disponible en: http://dspace. utalca.cl/retrieve/2562/carri\%3Fn moraga c.pdf

29. Méndez CE, Beltrán MA, Concha SC, Camacho PA. Relación entre Enfermedad Periodontal y Parto Pretérmino en el Servicio de Sala de Partos del Hospital Universitario de Santander (HUS) [Trabajo de Grado] Bucaramanga: Universidad Industrial de Santander, 2006.

30. Castellanos JL, Díaz LM. Embarazo, enfermedad sistémicas de alto riesgo y enfermedad periodontal. Perinatología y Reproducción humana 2009; 23: 65 - 73

31. Concha SC, Relación de la salud oral con las enfermedades crónicas en las personas mayores: una revisión. Ustasalud 2006; 5: $49-63$

32. Moore S, Ide M, Coward PY, Randhawa M. A prospective study to investigate the relationship between periodontal disease and adverse pregnancy outcome. Br Dent J 2004; 197: 251 - 258
33. Michalowicz BS, Hodges JS, DiAngelo AJ, Lupo VR, Novelle J, Ferguson JE, et al. Tratamiento de la enfermedad periodontal y riesgo de parto prematuro. Revista del Hospital Materno Infantil Ramón Sardá 2006; 26: 4 - 14. Traducción del original publicado en $\mathrm{N}$ England J Med 2006; 355: 1885 - 1894

34. López-Arranz E, Martínez AI. Repercusión de la patología periodental en el resultado final de la gestación. Patología periodontal materna y prematuridad. Revista Europea de Odontoestomatología. [Fecha de acceso: mayo de 2010]. URL disponible en: http://www.redoe.com/ver. php?id $=48$

35. Herrera JA, Vélez-Medina S, Molano R, Medina V, Botero JE, Parra B, Contreras A. Periodontal intervention effects on pregnancy outcomes in women with preeclampsia. Colomb Med 2009; 40: 177 - 184

36. Jared H, Boggess KA, Moss K, Bose C, Auten R, Beck J, Offenbacher $S$, Fetal exposure to oral pathogens and subsequent risk for neonatal intensive care admission. J Periodontol 2009; 80: $878-883$

37. Peña B. Problemas bioéticos y dilemas éticos contemporáneos. En Salud pública hoy. Enfoques y dilemas contemporáneos en salud pública. 2002 Editor Saul Franco p.80

38. Gómez da Silva Júnior A, Almeida C. Modelos assistenciais em saúde: desafios e perspectivas [Fecha de acceso: agosto 2010]. URL disponible en: http://assistenciafarmaceutica.fepese.ufsc.br/pages/arquivos/m_a_s.pdf

39. Starfield B. Basic concepts in populations' health and health care. J Epidemiol Community Health 2001; 55: 452 $-454$

40. Lara N, López V, Morales SL, Cortes E. Satisfacción de usuarios de dos servicios odontológicos. Revista ADM 2000; 7: 175 - 179

41. Universidad de Antioquia. Facultad de Salud Pública Héctor Abad Gómez. Dilemas en las decisiones en la atención en salud. Ética, deberes y derechos constitucionales. URL disponible en: http://guajiros.udea.edu.co/fnsp/cbvsp/investigaciones/atencionsaludsistemadesaludcolombiano.pdf

42. Brown LD, Franco LM, Rafeh N, Hatzell T. Garantía de la calidad de atención de salud en países en desarrollo. USAID URL disponible en: http://pdf.usaid.gov/pdf_docs/ PNACH089.pdf

43. Ministerio de Protección Social. Decreto 1011 de 2006

44. Coelho J. Modelos assistenciais em saúde. (Aprox. 16 p) (Agosto 2010) URL disponible en: http://ebookbrowse. com/modelos-assistenciais-pdf-d27756940

45. Boulet SL, Johnson K, Parker C, Posner SF, Atrash H. A perspective of preconcepcional health activities in the United States. Matern Child Health J. 2006; 10: $13-20$

46. Steel J. Cuidados pregestacionales. Diabetes Voice. 2002; 47: $9-12$

47. Whitworth M, Dowswell T. Promoción sistemática de la salud pregestacional para mejorar los resultados del embarazo. Biblioteca Cocharane plus. 2010; 1: (Aprox. 20 p) (Diciembre 2010) URL disponible en: http:// www.update-software.com/BCP/BCPGetDocument. asp?DocumentID = CD007536

48. Cáceres-Manrique FM. Control prenatal una reflexión urgente. Rev Colomb Obstet Ginecol 2009; 60: 165 - 170

49. OMS/OPS. Manual sobre el enfoque de riesgo en la atención materno infantil. 1986

50. OPS, CLAP, SMR. Guías para el continuo de atención de la 
mujer y el recién nacido focalizadas en APS. $2^{\text {a }}$ edición. Publicación científica No.1573 - 2010

51. SDS. Cero indiferencia con la mortalidad materna y perinatal URL disponible en: http://www.saludcapital. gov.co/Publicaciones/Desarrollo\%20de\%20Servicios/ Gu\%C3\%ADas\%20para\%20la\%20atenci\%C3\%B3n\%20 Materno\%20Perinatal/Pol\%C3\%ADtica\%20salud\%20materna\%20mayo\%20de\%202007.pdf

52. Organización Mundial de la Salud. Trabajando con individuos, familias y comunidades para mejorar la salud materna y neonatal. 2010

53. Pécora A, San Martín ME, Cantero A, Furfaro K, Jankovic MP, Llompart V. Control prenatal tardío: ¿Barreras en el sistema de salud? Rev Hosp Mat Inf Ramón Sardá 2008; 27 (3): $114-119$

54. Vélez C, Gómez DE, González MC. Errores y equivocaciones por acción u omisión en acciones de promoción y prevención dirigidas a gestantes en Manizales, 2007. Hacia la promoción de la salud. 2008; 13: 61-76

55. California Dental Ass- American College of Obstetrician and Gynecologist. District IX. Oral Health during pregnancy and early child. Evidence-Based Guidelines for health professionals. February 2010. URL disponible en: http:// www.cdafoundation.org/library/docs/poh_guidelines.pdf

56. Ministerio de Salud. Resolución 412 de 2000

57. Guías de promoción de la salud y prevención de enfermedades en la salud pública

58. Callejo KV, Villegas P, Gutiérrez MM. Mitos durante la atención odontológica en el embarazo. URL disponible en: http://salud.edomexico.gob.mx/imiem/doc/abstrac20.pdf

59. Fuentes R, Oporto G, Alarcón AM, Bustos L, Prieto R, Rico $\mathrm{H}$. Opiniones y creencias de embarazadas en control prenatal relacionadas con salud oral y embarazo. Av Odontoestomatol 2009; 25: 147-154

60. Saddki N, Yusoff A, Hwang YL. Factors associated with dental visit and barriers to utilization of oral health care service in a simple of neonatal mothers in Hospital Universiti Sains Malaysia. BMC Public Health 2010; 10: 75

61. Miraschi C, Ríos M, Urzúa JP, Barahona P. Calidad de vida y condición de salud oral en embarazadas chilenas e inmigrantes peruanas. Rev Perú Med Exp Salud Pública. 2009; 26: 455 - 461

62. Saldarriaga OJ, Sánchez M, Avendaño L. Conocimientos y prácticas en salud bucal de las gestantes vinculadas al programa de control prenatal. Medellín 2003. 2004 CES Odontol. 17: 9 - 23

63. Marc JNC, Plutzer K, Plutzer k. Women attitudes to and perceptions of oral health and dental care during pregnancy. J Perinat Med 2010; 38: 3-8

64. Cordova JA, Bulnes RM. Nivel de conocimiento sobre prevención de salud bucal en gestantes. Hospital de la mujer Villahermosa, Tabasco 2007, Horizonte Sanitario. 2007; 6:18 - 25

65. Díaz RM, Carrillo M, Terrazas JF, Canales CE. Actitudes que influyen en la demanda de servicios odontológicos durante la gestación, Revista ADM. 2001;7: 68 - 73

66. Romero Y. Representaciones sociales del profesional de la salud bucal. ODOUS CIENTÍFICA. 2007; 8: 21 - 32

67. Zanata RL, Fernández KBP, Navarro PSL. Prenatal dental care: Evaluation of professional knowledge of obstetricians and dentist in the cities of Londrina and Bauru. J Appl Oral Sci.2008; 16: 194 - 200
68. Pachas FM, Sánchez YD, Carrasco MB, Suárez M, Villena R. Perfil de atención de salud en gestantes y niños de 0-71 meses de edad, de un puesto de salud del Cono MoreteCarabayllo, Lima-Perú. Rev Estomatol Herediana.2008;18: $83-92$

69. Ayala de la Vega GR. Impacto social de los programas de salud oral en gestantes del centro de salud Carmen de la legua Reynoso-Callao 2001. Universidad Nacional Mayor de San Marcos. Facultad de Odontología. Tesis para optar el título de Magíster en Estomatología. 2004 En: http://www.cybertesis.edu.pe/sisbib/2004/ayala_vg/pdf/ ayala_vg-TH.back.1.pdf

70. Thomas NJ, Middleton PF, Crowther CA. Oral and dental health care practices in pregnant women in Australia: a postnatal survey. BMC Pregnancy and childbirth 2008; 8 (13). URL disponible en: http://www.biomedcentral. com/1471-2393/8/13

71. Casals E. El acceso a los servicios de salud oral: ¿es un problema en Europa? ¿y en España?. En: Las nuevas prestaciones y los nuevos retos de la salud oral en España. Jornada de invierno SESPO 2008: 7 - 24

72. Londoño AM, Salcedo AM, Silva IC, Vera L, Cruz C. Enfermedad periodontal y preclampsia. Revisión de la literatura. Rev Estomat. 2009; 17: $38-44$

73. Couto MD, Vásquez N, Esser J. Antropología médica: Una necesidad hacia una mayor humanización en la odontología. URL disponible en: http://www2.scielo.org.ve/pdf/ rce/v17n30/art06.pdf

74. Franco AM, Ochoa E, Martínez E. Reflexiones para la construcción de política pública con impacto en el componente bucal de la salud. Rev Fac Odont Univ Ant 2004; 15: 78 - 90

75. Ministerio de Protección Social. Ley 1122 de 2007

76. Ministerio de Protección Social. Decreto 3039 de 2007

77. Ministerio de Protección Social. Resolución 425 de 2008

78. Barrios de León E. "Factores de riesgo de la mortalidad materna en el departamento de San Marcos". Guatemala 2004 En: http://desastres.cies.edu.ni/digitaliza/tesis/ t293/seccionb3.pdf 